Boise State University ScholarWorks

Civil Engineering Faculty Publications and

Presentations

Department of Civil Engineering

5-22-2011

\title{
The Adaptability and Sustainability of Surface Water Diversions Along the Main Stem of the Snake River in Southern Idaho
}

David J. Hoekema

Boise State University

Venkataramana Sridhar

Boise State University

Xin Jin

Boise State University 


\title{
The Adaptability and Sustainability of Surface Water Diversions Along the Main Stem of the Snake River in Southern Idaho
}

\author{
D. J. Hoekema, V. Sridhar, and X. Jin \\ Boise State University
}

\begin{abstract}
Agriculture in southern Idaho depends heavily on the conversion of snowpack into spring runoff. The Natural Resource Conservation Service (NRCS) has developed a Surface Water Supply Index (SWSI) as a tool to predict whether or not forecasted runoff and reservoir storage will be adequate to meet irrigator's needs at a basin scale. This research by comparing SWSI to diversions for individual canals advances the use of SWSI to develop a Surface Water Supply Metric (SWSM) that can be used to estimate the reliability and sustainability of diversions under historic and projected time periods. An historic analysis of diversions during three time periods 1928-1957, 1960-1980, and 19802009 indicates how the construction of Palisades Reservoir in 1956 allowed some canals to increase diversions, while other canals where able to improve the reliability of diversions. The analysis also highlights how decreasing diversions by irrigators (10\% and $13 \%$ in July and August, respectively) from the Twin Falls North Side Canal Compnay has increased diversion reliability in those months. The second section of the research uses the SWSM to assess the sustainably of diversions under three projected climate change scenarios. All projected flow scenarios were run using a system dynamics version of the Snake River Planning Model (SRPM) developed by the authors. SRPM is currently used by the Idaho Department of Water Resources (IDWR) to plan water resource management in the Snake River basin. The analysis indicates based on the projected climate scenarios analyzed that upstream irrigators may see a significant decline in reliability while downstream users may see improved irrigation reliability.
\end{abstract}

\section{Introduction}

How sustainable is farming in the desert? The Snake River Plain in southern Idaho has an arid to semi-arid climate with precipitation across the plain ranging from 150-400 mm. Yet this desert has sustained substantial agricultural development for nearly 100 years. The early agricultural development was made possible by surface water diversions from the Snake River and its tributaries. But how sustainable are surface water diversions in the Snake River in a changing climate? The research presented here presents a historic analysis of canal diversions from 1928-2005 and develops a supply metric that can be used to determine the sustainability of diversions under projected climate change from the supply perspective. This supply metric is based on the Surface Water Supply Index (SWSI) developed by the Natural Resource Conservation Service (NRCS) (www.wcc.nrcs.usda.gov/ wsf /swsi.html). SWSI is an important index for water management purposes. SWSI uses forecasted runoff and current reservoir storage to determine the likelihood of adequate surface water supply in a given year. The SWSI index is updated by NRCS for 16 basins in Idaho each year, including the Snake River below Heise.

While primarily developed as a forecasting tool, SWSI has been used recently to estimate surface water demand in the Snake River (Scott, 2010; Hoekema, 2011, in review). SWSI is a powerful tool for understanding how changes in supply and demand impact surface water diversions. The index is based on the two main sources of surface water supply in the basin: natural flow and storage. Irrigators in the basin are allowed to divert water based on the priority of their natural flow and storage rights. Water rights in Idaho are based on the Priority Doctrine, in which users who first appropriated water for a beneficial use have first priority to that water during times of shortage (Slaughter, 2004). Priority rights are assigned both to natural flow and storage. Reservoirs must pass natural flow rights with priority dates older than the reservoir storage rights downstream. 


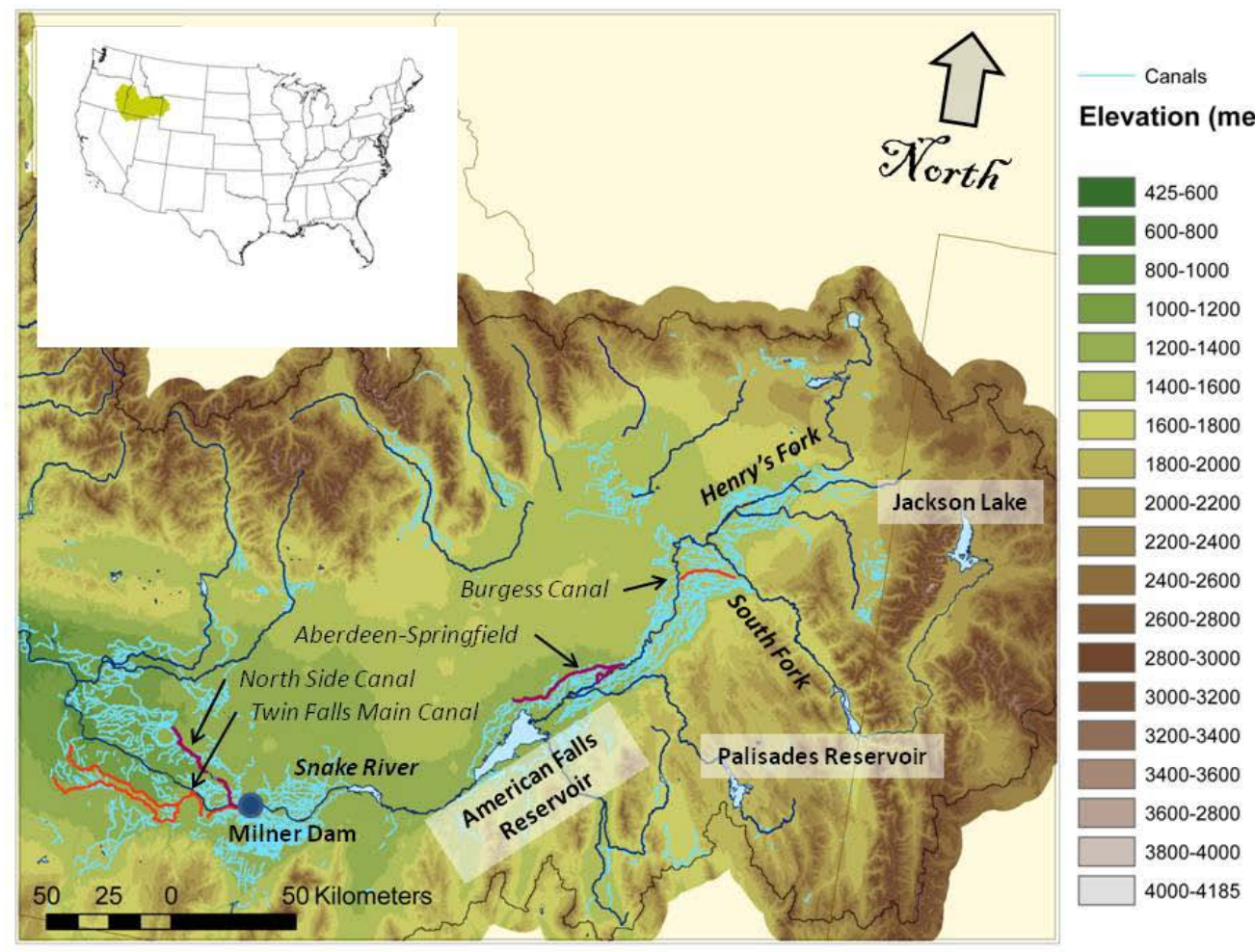

Figure 1. Study Area Map Showing the Location of the Seven Canals and Three Surface Water Irrigated Regions Included in this Study

When there are multiple reservoirs in a river, as with the Snake River (see Figure 1), water managers typically try to hold storage water as far upstream as possible, to minimize spills in the lowest reservoir. For the purpose of the research presented here, especially in understanding SWSI, it is critical to understand that while reservoirs typically fill in a pattern that maximizes total storage in the system, the storage rights in the system fill, from an accounting perspective, by priority date (personal communication, Olenichak, 7-27-2009). For example from an accounting perspective American Falls storage water with a priority date of 1921 will often fill before Palisades storage rights with a junior priority right of 1939. However, physically, American Falls water may be stored in Palisades Reservoir. It is by this means that American Falls water can be delivered upstream of the reservoir as indicated by storage rights in Table 1. The storage rights for each canal are shown in Table 1. Canal storage rights were based on Water District 1 Storage assessment for 2010 (www.waterdistrict1.com/ WD01\%20Storage\%20Report.pdf, 2011). The storage/diversion represents the ratio of storage rights to mean annual diversions (May-Sept) between 1928 and 2009.

Table 1. Storage Rights (in acre-feet) for Seven Canals in the Snake River Basin by Location and Date.

\begin{tabular}{|c|c|c|c|c|c|c|}
\hline Canal & $\begin{array}{l}\text { Storage/ } \\
\text { diversion }\end{array}$ & $\begin{array}{c}\text { Jackson Lake } \\
\text { (1906-1913) }\end{array}$ & $\begin{array}{l}\text { Palisades } \\
\text { WWS } \\
\text { (1921) }\end{array}$ & $\begin{array}{c}\text { American } \\
\text { Falls WWS } \\
\text { (1921) }\end{array}$ & $\begin{array}{c}\text { American } \\
\text { Falls } \\
\text { (1921) }\end{array}$ & $\begin{array}{c}\text { Palisades } \\
\text { (1939) }\end{array}$ \\
\hline Enterprise & 0.94 & 11252 & 1820 & & 8779 & 14780 \\
\hline Burgess & 0.27 & 10603 & 8000 & & 9343 & 23400 \\
\hline Blackfoot & 0.28 & 7370 & 4050 & & 12558 & \\
\hline $\begin{array}{l}\text { Aberdeen- } \\
\text { Springfield }\end{array}$ & 0.90 & 70703 & 22860 & & 52263 & 110418 \\
\hline Riverside & 0.05 & & 1180 & & & 320 \\
\hline $\begin{array}{l}\text { Twin } \\
\text { FallsNorth } \\
\text { Side }\end{array}$ & 0.92 & 312007 & 116600 & 9248 & 422043 & \\
\hline $\begin{array}{l}\text { Twin Falls } \\
\text { Main }\end{array}$ & 0.28 & 97183 & & 147582 & 1165 & \\
\hline
\end{tabular}


While we recognize that the sustainability of agriculture depends on more than supply, we feel a critical first step in assessing the sustainability of diversions under climate change is to develop a surface water supply metric by which diversion sustainability can be assessed on a canal-by-canal basis in the basin. When changes in management are proposed to develop a more sustainable water resource system, the reliability of diversions based on changes in management can be assessed quickly. The first step of the research develops the Surface Water Sustainability Metric (SWSM) that defines sustainability by reliability, $R$, and minimum supply, $S$. The historic analysis on which the SWSM is developed for each canal provides the stakeholder a level of confidence and basis to intuitively understand the metric. The second step of the research applies the metric to assess the sustainability of diversions under climate change for the Enterprise Canal, Burgess Canal, Blackfoot Canal, Aberdeen-Springfield Canal, Riverside Canal, Twin Falls North Side Canal, and Twin Falls Main Canal. The locations of the larger canals are shown in Figure 1.

\section{Study Area}

The seven canals included in this study divert water from the Snake River, in southeast Idaho. There are three distinct surface water irrigation regions in which these canals are located. The Enterprise and Burgess Canals divert streamflow from the South Fork of the Snake River upstream of the Henry's Fork. The Blackfoot Canal, Aberdeen-Springfield Canal, and Riverside Canal divert flow from the mainstem of the Snake River below the Henry's Fork. The Twin Falls Main Canal and North Side Canal divert water from the Snake River at Milner Dam. Historically, Region 1, which relies primarily on natural flow to meet crop water demand, is the least prone to shortages and has the oldest natural flow rights. Region 3, since the construction of American Falls Reservoir, has also had a reasonably secure supply. Region 2 has been most prone to shortages (Feige, 2000), because the water rights are typically junior to those in Region 1 and a natural sink in the Snake River upstream of Blackfoot causes a large portion of natural flow to bypass canal headgates in this region each year. A portion of the flow in the Blackfoot reach sinks into the highly permeable basalt flows underlying the river and then reemerges underneath American Falls Reservoir to provide natural flow to Region 3 (Kjelstrom, 1995).

\section{Methods and Materials}

Surface Water Supply Index. The following method describes the Surface Water Sustainability Metric (SWSM) developed for seven canals included in the study. SWSM is based on SWSI. NRCS has calculates SWSI for the Snake River below Heise for nine months, January through September, from 1971-2010. In this research the SWSI index was extended for the month of July back to 1928. The method for calculating SWSI in an Excel spreadsheet is as follows:

1) Column 1: Years within index

2) Column 2: End-of-month EOM reservoir storage

3) Column 3: Sum of monthly naturalized flow through September

4) Column 4: Supply = (Column $2+$ Column 3)

5) Column 5: Rank of year based on Column 4 in from highest to lowest supply

6) Column 6: Non-exceedance probability $=(1-(\operatorname{Rank} /(n+1))$, where $n=$ number of years ranked

7) Column 7: SWSI (or NFI) $=((($ non-exceedance probability * 100) -50$) / 12)$

NRCS includes the EOM storage in Jackson Lake and Palisades in their SWSI index at Heise. In our calculation of SWSI at Heise we added EOM storage in American Falls Reservoir. This seems to significantly improve the correlation of diversions to SWSI, especially in regions 1 and 2, which depend more heavily on junior water rights within in Palisades Reservoir. As mentioned earlier these storage rights are the last to fill from an accounting perspective, since they are the most junior. Also because American Falls is the largest reservoir on the Snake River by including the reservoir we better represent the proportion of natural flow and storage within the basin. A second SWSI index based on natural flow at Neeley, below American Falls Reservoir was used for analysis of diversions in Region 3. Natural flow at Neeley was only available in the NRCS online archive from 1927 to 2008.

Calculating SWSM with SWSI over Historic Periods. When diversions are plotted with their associated SWSI values a piecewise correlation emerges as shown in Figure 2, which presents diversions on the Burgess Canal prior to the filling of Palisades Reservoir. (Diversions data provided by IDWR are measured in thousand acre-feet $\left.(\mathrm{kaf})=1233 \mathrm{~m}^{3}\right)$. The rising limb of the piecewise function indicates the limitation imposed on diversions due to water rights, while the flat limb of the piecewise function represents the demand limited portion of the curve (Scott, 2010; Hoekema, 2011). The flat limb denotes the full supply demand, FS, and is calculated as the mean of diversions occurring after the breakpoint in the piecewise function. As will be seen in 
the Results section of this manuscript, FS may fluctuate over different time periods due to increased storage rights or increased efficiency of deliveries or decreased demand.

\section{Burgess Canal July Diversions: 1928-1957}

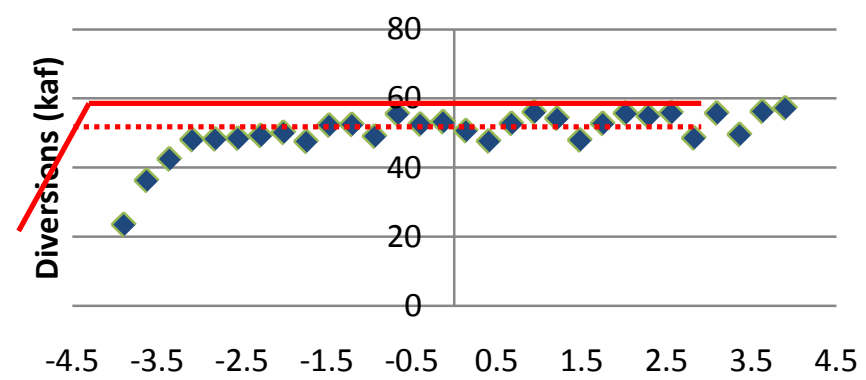

Surface Water Supply Index (SWSI)

Figure 2. A Typical Piecewise Relationship between Diversions and SWSI Based on Analysis of July Diversions on the Burgess Canal from 1928-1957.

To determine the reliability of diversions in any given period the minimum full supply, MFS, demand was determined by subtracting FS by 2 standard deviations from the mean. MFS is shown in Figure 2 as a dashed line. The SWSI value, at the intersection of the MFS and the rising limb is then referred to as $i$. The closest plotted SWSI value $\leq i$ is then referred to as $N$. The reliability of diversions, $\mathrm{R}$, in the study period is then calculated as $(1-\mathrm{N} / \mathrm{n})$, where $\mathrm{n}$ equals the number of years for which diversions and SWSI are plotted. The SWSM then becomes (R, S), where $S$ is the supply at $R$ for a historic period.

SWSM and Projected Climate Scenarios. To test the application of the SWSM index, we calculated $R_{p}$ based on naturalized flow generated by a hydrologic model run using downscaled climate data from three global climate models (GCMs) under the A1B emission scenario (Nakićenović et al., 2000). The naturalized flow was fed into the System Dynamics-Snake River Planning Model (SD-SRPM) reservoir operations model (Hoekema, 2011, in review). $R_{p}$ was calculated based on EOM and naturalized flow at Heise and Neeley. The three GCM's included the ECHO model (Legutke and Voss, 1999) developed at the Max-Planck-Institute for Meteorology, the Community Climate System Model (CCSM3) model developed by the National Center for Atmospheric Research (NCAR, http://www.cesm.ucar. edu/index.html) in the United States, and the Parallel Climate Model (PCM1) developed jointly by the Los Alamos National Laboratory, the Naval Postgraduate School, the U.S. Army Corps of Engineers' Cold Regions Research and Engineering Lab, and NCAR (www.cgd. ucar.edu/pcm/). The ECHO model represents a decrease in precipitation by about $15 \%$ and increase in temperature of $5.5^{\circ} \mathrm{C}$. The CCSM3 and PCM1 models represent little change in precipitation, but a temperature increase of $4^{\circ} \mathrm{C}$ and $3^{\circ} \mathrm{C}$ by 2099. The change in temperature and precipitation is based on historic mean temperature and precipitation for the periods 1949-1999.

The downloaded bias-corrected and spatially downscaled projected climate data described by Maurer et al (2007) and obtained from USBR (http://gdo-dcp.ucllnl.org/downscaled cmip3projections) from the GCMs are coarse. The spatial resolution is 1/8 degree and time resolution is monthly. Since we required daily precipitation and temperature data for hydrological modeling, we temporally disaggregated to a daily time step. Using these downscaled climate model outputs, we simulated stream flows for each future scenario.

Before using the hydrologic model for future prediction, we used historic meteorological data from the Snake River basin to drive the Variable Infiltration Capacity (VIC) hydrologic model (Liang et al., 1994) for calibration. Calibration was run on a daily time-step for a 51-year calibration period between 1928 and 1978. The simulated daily streamflow for this period was aggregated into monthly average flows at the locations of interest by using the routing model (Lohmann et al., 1998). The VIC generated flows were then compared to natural flows reconstructed by IDWR to verify the VIC model performance. An automatic global search optimization method -- Shuffling Complex Evolutionary (SCE) algorithm proposed by Duan et al (1992) was integrated with the VIC model for Snake River basin parameter characterization. Because the SCE calibration technique is computationally intensive, parallelization of VIC model was necessary. In this study, a parallel version of VIC model was developed and used with SCE model for calibration work. The simulated historical streamflow data after calibration was compared with observed ones for the period of 1979-2005 for validation. 
This is an author-produced, peer-reviewed version of this article. The final, definitive version of this document can be found online at Proceedings of the 2011 World Environmental and Water Resources Congress, published by American Society of Civil Engineers. Copyright restrictions may apply. DOI: 10.1061/41173(414)174

\section{Results and Discussion}

The results of the historical analysis of R and S using three historic periods 1928-1957, 1960-1980, and 19802009 indicate that while Palisades Reservoir significantly increased supply in the basin, the results of reservoir increased storage rights depended very much on the unique characteristics of the canal company. Table 2 shows the change in reliability of diversions by canal and region. Analysis of diversions indicates that the Enterprise Canal which has storage rights equal to 94\% of its May-Sept average annual diversion from (1928-2009) was unable to establish a minimum full-supply demand prior to construction of Palisades Reservoir. Storage rights in Palisades nearly doubled the storage rights of the canal and vastly improved the reliability and quantity of flow that could be diverted between July and September. The Enterprise Canal is has an unusually heavy reliance on storage rights, not common in Region 1. The Burgess Canal storage right/diversion ratio of 0.27 had a much more reliable supply prior to acquiring rights in Palisades Reservoir. The acquisition of the rights allowed diversions to increase during years with high supply represent by SWSI $>0$. The result is a step function shown in Figure 3. Figure 3 represents diversions in the Burgess Canal from 1928 to 2009. The blue diamonds embedded with smaller red diamonds indicate diversions prior to the construction of Palisades Reservoir. Interestingly the reliability of September diversions declined dramatically in the recent period for both the Burgess and Enterprise Canal.

The three canals analyzed in Region 2 represent various levels of reliance on storage the diversion/storage ratio is 0.05 for the Riverside Canal, 0.28 for the Blackfoot Canal, and 0.90 for the Aberdeen-Springfield Canal. The historic analysis of diversions to the SWSI index indicates that the Riverside Canal has a highly dependable natural flow right. The additional storage appears to have had little impact on diversion reliability and fullsupply demand. However the large acquisition of storage rights in Palisades appears to have greatly increased the reliability of July-September diversions in the basin. The Blackfoot Canal, which owns none of the junior storage rights in Palisades saw no increase in full-supply diversions.

Table 2. Change in Reliability of Historic Diversions

\begin{tabular}{|c|c|c|c|c|c|c|c|c|c|c|}
\hline Region & Period & \multicolumn{3}{|c|}{ Enterprise } & \multicolumn{3}{|c|}{ Burgess } & July & Aug. & Sept. \\
\hline \multirow{3}{*}{ Region 1} & $1928-2057$ & $0 \%$ & $0 \%$ & $0 \%$ & $90 \%$ & $87 \%$ & $87 \%$ & & & \\
\hline & 1960-1989 & $100 \%$ & $80 \%$ & $90 \%$ & $90 \%$ & $90 \%$ & $87 \%$ & & & \\
\hline & 1980-2009 & $83 \%$ & $73 \%$ & $66 \%$ & $100 \%$ & $73 \%$ & $66 \%$ & & & \\
\hline & & \multicolumn{3}{|c|}{ Blackfoot } & \multicolumn{3}{|c|}{ Aberdeen-Springfield } & \multicolumn{3}{|c|}{ Riverside } \\
\hline \multirow{3}{*}{ Region 2} & $1928-2057$ & $90 \%$ & $80 \%$ & $87 \%$ & $80 \%$ & $80 \%$ & $0 \%$ & $100 \%$ & $100 \%$ & $100 \%$ \\
\hline & 1960-1989 & $97 \%$ & $100 \%$ & $97 \%$ & $100 \%$ & $100 \%$ & $90 \%$ & $100 \%$ & $100 \%$ & $100 \%$ \\
\hline & 1980-2009 & $87 \%$ & $87 \%$ & $73 \%$ & $100 \%$ & $87 \%$ & $77 \%$ & $100 \%$ & $100 \%$ & $100 \%$ \\
\hline \multicolumn{5}{|c|}{ Twin Falls North Side } & \multicolumn{3}{|c|}{ Twin Falls Main } & & & \\
\hline \multirow{3}{*}{ Region 3} & $1928-2057$ & $97 \%$ & $84 \%$ & $87 \%$ & $97 \%$ & $100 \%$ & $90 \%$ & & & \\
\hline & 1960-1989 & $100 \%$ & $92 \%$ & $93 \%$ & $100 \%$ & $100 \%$ & $90 \%$ & & & \\
\hline & 1980-2009 & $100 \%$ & $87 \%$ & $100 \%$ & $90 \%$ & $90 \%$ & $100 \%$ & & & \\
\hline
\end{tabular}

The Twin Falls North Side Canal and the Twin Falls Main Canal which own none of the junior water rights in the Palisades Reservoir as expected, also saw no increase in diversions after the construction of Palisades Reservoir, but the Twin Falls Main Canal has undergone a decline in reliability while maintaining a nearly constant full-supply demand for nearly 100-years. The North Side Canal on the other hand, has actually increased reliability by reducing full-supply demand in July and August by $10 \%$ and 13\% respectively. 
July Diversions: Burgess Canal

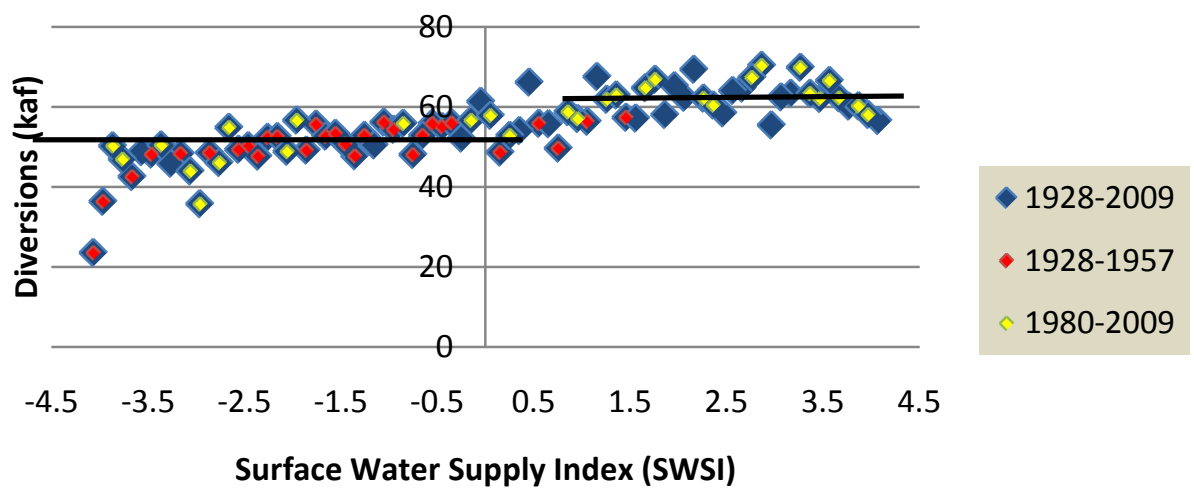

Figure 3. Illustration of the Stepped Relationship of Diversions on the Burgess Canal Caused by the Acquisition of Storage Rights in Palisades Reservoir.

The projected climate change analysis which focused on the reliability of September diversions (as shown in Table 3), $R_{p}$, based on the SWSM (R, S) of the recent period 1980-2009 for the canals in Region 1 and Region 2 , and the entire historic period for Region 3. The SWSM for entire historic period was used to analyze impact of climate change in Region 3 since no shortages were identified in the recent period during the month of September. Under projected climate change scenarios, PCM1 predicts greater reliability of supply for all seven canals. CCSM3 predicts decreasing reliability for the canals in Region 1, increasing reliability in Region 2, and fairly steady reliability in Region 3 . The big decline in reliable for the middle period in the CCSM3 model is the result of two multi-year droughts. One of those droughts lasts 12 years from 2060-2072. The ECHO model predicts declining reliability in all but the Aberdeen-Springfield Canal, where reliability while starting somewhat below current levels increases in the following two time periods.

Table 3. Projected September Reliability for 6 Canals in the Snake River Basin by Region

\begin{tabular}{|c|c|c|c|c|c|c|c|}
\hline \multirow{3}{*}{ Region } & & PCM1 & CCSME & ECHO & PCM1 & CCSM & ECHO \\
\hline & Period & \multicolumn{3}{|c|}{ Enterprise } & \multicolumn{3}{|c|}{ Burgess } \\
\hline & 1980-2009 & \multicolumn{3}{|c|}{ SWSM (66\%, 3784 kaf) } & \multicolumn{3}{|c|}{ SWSM (66\%, 3784 kaf) } \\
\hline \multirow{3}{*}{ Region 1} & $2011-2040$ & $90 \%$ & $60 \%$ & $43 \%$ & $90 \%$ & $60 \%$ & $43 \%$ \\
\hline & $2041-2070$ & $83 \%$ & $37 \%$ & $47 \%$ & $83 \%$ & $37 \%$ & $47 \%$ \\
\hline & 2071-2099 & $93 \%$ & $38 \%$ & $34 \%$ & $93 \%$ & $38 \%$ & $34 \%$ \\
\hline & & \multicolumn{3}{|c|}{ Blackfoot } & \multirow{2}{*}{\multicolumn{3}{|c|}{$\begin{array}{l}\text { Aberdeen-Springfield } \\
\text { SWSM (77\%, } 3318 \text { kaf) }\end{array}$}} \\
\hline & 1980-2009 & SWSN & $(73 \%, 3$ & kaf) & & & \\
\hline \multirow{3}{*}{ Region 2} & $2011-2040$ & $93 \%$ & $73 \%$ & $53 \%$ & $97 \%$ & $83 \%$ & $70 \%$ \\
\hline & $2041-2070$ & $93 \%$ & $50 \%$ & $70 \%$ & $97 \%$ & $60 \%$ & $80 \%$ \\
\hline & 2071-2099 & $97 \%$ & $83 \%$ & $59 \%$ & $97 \%$ & $90 \%$ & $76 \%$ \\
\hline & & \multirow{2}{*}{\multicolumn{3}{|c|}{$\begin{array}{l}\text { Twin Falls North Side } \\
\text { SWSM (91\%,3353 kaf) }\end{array}$}} & \multirow{2}{*}{\multicolumn{3}{|c|}{$\begin{array}{c}\text { Twin Falls Main } \\
\text { SWSM }(91 \%, 3353 \text { kaf) }\end{array}$}} \\
\hline & $1928-2008$ & & & & & & \\
\hline \multirow{3}{*}{ Region 3} & $2011-2040$ & $100 \%$ & $90 \%$ & $80 \%$ & $100 \%$ & $90 \%$ & $80 \%$ \\
\hline & 2041-2070 & $100 \%$ & $63 \%$ & $87 \%$ & $100 \%$ & $63 \%$ & $87 \%$ \\
\hline & 2071-2099 & $100 \%$ & $90 \%$ & $83 \%$ & $100 \%$ & $90 \%$ & $83 \%$ \\
\hline
\end{tabular}

\section{Conclusions}

The research presented here takes a key step toward defining the sustainability of agriculture in Idaho under climate change is to develop a metric that can be used to determine whether or not we will have adequate supply in the future. While there are many factors that will determine whether not current agriculture is sustainable, including environmental and social factors, the development of SWSM is a first step toward understanding sustainability from a volumetric standpoint at the canal scale. The use of the SWSM can be a quick and 
efficient method to considering climate impacts on specific diversions based on a large number of climate scenarios. In the future further studies could assess how changes in projected irrigation efficiency would change SWSM. The use of NFI and SWSI to derive SWSM allows a user to differentiate how irrigators who rely on natural flow versus storage rights will be impacted by changes in climate. The apparent shift toward increased shortages in the upstream portion of the basin, will pose an interesting challenge for managing water rights. Historically senior water users have enjoyed water during times of shortage. It now appears that junior water users who bought early storage rights may have a more reliable water supply in the future. 


\section{References}

Duan, Q., Sorooshian, S., and Gupta, V. (1992). "Effective and efficient global optimization for conceptual rainfall-runoff models”. Water Res Res, 28(4):1015-1031.Fiege M (2000). Irrigated Eden: The making of an agricultural landscape in the American West. University of Washington Press, Seattle WA, 98145-5096.

Hoekema, D. J. (2011, in review). “A System Dynamics Approach for Climate Impact Studies in the Snake River Basin.” Boise State University, Boise, ID 83706.

Kjelstrom, L. C. (1995). Streamflow gains and losses in the Snake River and groundwater budgets for the Snake River Plain, Idaho and eastern Oregon, US Geological Survey Water-Resources Investigation Report 03-4244.

Legutke, S. and Voss, R. (1999), The Hamburg Atmosphere-Ocean Coupled Circulation Model ECHO-G. Technical report, No. 18, German Climate Computer Centre (DKRZ), Hamburg, 62 pp.

Liang X., Lettenmaier D. P., Wood E. F., Burges S. J. (1994). “A Simple Hydrologically Based Model of Land Surface Water and Energy Fluxes for General Circulation Models,” Journal of Geophysical Research 99(D7): 14415-14428.

Lohmann, D., Raschke, E., Nijssen, B., and Lettenmaier, D. P. (1998). "Regional scale hydrology: I. Formulation of the VIC 2L model coupled to a routing model”. Hydrological Sciences 43(1), 131-141.

Maurer, E., 2007. "Uncertainty in hydrologic impacts of climate change in the Sierra Nevada, California, under two emission scenarios”, Climate Change, 82, 309-325.

Nakićenović N, Swart R (eds.) (2000). “Special Report on Emissions Scenarios,” A Special Report of Working Group III of the International Panel on Climate Change. Cambridge University Press, Cambridge, United Kingdom and New York, NY, USA.

Scott, K (2010). "Modeling energy implication of water management decisions on the Eastern Snake River Plain.” University of Idaho, Moscow, ID 83844.

Slaughter, R. A. (2004). Institutional history of the Snake River 1850-2004, Climate Impacts Group, University of Washington, Seattle, WA 98195-5672. 